\title{
Performance analysis of photovoltaic plants installed in dairy cattle farms
}

\author{
Remo Alessio Malagnino \\ Department of Agricultural and Food Sciences, University of Bologna, Italy
}

\begin{abstract}
Electric production from renewable resources, such as solar photovoltaic (PV), is playing an increasingly essential role in the agricultural industry because of the progressive increase in the energy price from fossil fuels and the simultaneous decrease in the income deriving from farming activities. A central issue in the sustainable diffusion of PV technologies is represented by the actual energy efficiency of a PV system. For these reasons, a performance analysis has been carried out in order to assess the potentials offered by different PV plants within a defined geographical context with the aim of investigating the impact of each component has on the PV generator global efficiency and defining the main technical parameters that allow to maximise the annual specific electric energy yield of an architectonically integrated plant, installed in a dairy house, compared to a ground-mounted plant. The annual performances of three grid connected PV plants installed in the same dairy cattle farm have been analysed: two are architectonically integrated plants - i.e., a rooftop unidirectional and a multi-field systems (both $99 \mathrm{~kW}_{\mathrm{p}}$ ) - and the other is a ground-mounted plant $\left(480 \mathrm{~kW}_{\mathrm{p}}\right)$. Furthermore, the electrical performances, estimated by the photovoltaic geographical information system (PVGIS), developed by the EU Joint Research Centre, and by an analytical estimation procedure (AEP), developed on the basis of a meteo-climatic database related to the records of the nearest weather station and integrated by the components' technical specifications, have been compared with the actual yields.

The best annual performance has been given by the ground-mounted PV system, with an actual increase of $26 \%$ and in the range of $6 \div 12 \%$ according to different estimations, compared to the integrated
\end{abstract}

Correspondence: Remo Alessio Malagnino, Department of Agricultural and Food Sciences (DISTAL), University of Bologna, viale G. Fanin 50, 40127 Bologna, Italy.

E-mail: remo.malagnino2@unibo.it

Key words: Animal houses; roofs; photovoltaic plant; forecasting model.

See online Appendix for symbology.

Received for publication: 9 February 2015.

Accepted for publication: 7 May 2015.

CC Copyright R.A. Malagnino, 2015

Licensee PAGEPress, Italy

Journal of Agricultural Engineering 2015; XLVI:455

doi:10.4081/jae.2015.455

This article is distributed under the terms of the Creative Commons Attribution Noncommercial License (by-nc 3.0) which permits any noncommercial use, distribution, and reproduction in any medium, provided the original author(s) and source are credited. systems, which were globally less efficient (average total loss of $26 \div 27 \%$ compared to $24 \%$ of the ground-mounted system). The AEP and PVGIS software estimates showed a good level of reliability for mean deviations between the annual actual and estimated electrical power yields have been equal to $11.5 \%$ for each PV system given the actual irradiation' $s$ uncertainty during the examined year. The main technical parameters, crucial to maximise the energy yield from a ground-mounted PV system to an integrated one, have been identified in the Tilt and Azimuth angles. Indeed, once a variance of $3 \div 4 \%$ in the global efficiency has been confirmed when the type of PV system is changed, in the case of the unidirectional integrated PV plant, the high roof pitch and the almost South orientation guarantee a solar energy increase up to $18 \%$ higher than that obtainable on the horizontal plane and similar to the increase estimated for the ground-mounted generator (+20\%). Hence, integrated PV systems, besides reaching the same levels of energy efficiency as those ground-mounted, are also more sustainable than the latter. This is true providing that there are both a suitable orientation and an accurate design, especially to prevent the PV panels' warming during summer, on an already available surface that is, however, functional to the roof's architecture.

\section{Introduction}

Like many other production industries, agriculture is also facing the problem of the increasing dependence on sources of energy such as electricity, oil and natural gas (Karkacier et al., 2006). In effect, agricultural and farming activities require high levels of energy inputs (Pelletier et al., 2011). At the same time, agriculture can meet directly these needs thanks to the natural resources available (e.g., biomass) that are through small systems of energy generation from renewable resources (Bianco et al., 2014; Castellano, 2014).

Electricity production from photovoltaic systems (hereinafter PV systems), which is the most common renewable energy technology, shows a great potential for farms and, particularly, for dairy cattle farms thanks to the considerable availability of surfaces and their high electric power consumption (Kraatz, 2007; Bayod-Rùjila et al., 2011).

For these reasons, PV systems are highly employed both as rooftop integrated plants and ground-mounted plants. The latter has entailed, however, a large consumption of agricultural land driven by the favourable system of public incentives in place (Frascarelli and Ciliberti, 2011). From 2009 to 2010, in fact, the power installed in nonintegrated plants has increased of $146 \%$, as it is the occupation of agricultural land (GSE, 2010). However, since 2011 through the introduction of the Ministerial Decree of 5 May 2011 (IV Conto Energia) followed by the Decree-law of 24 January 2012 (Decreto Liberalizzazioni) (Italian Regulation, 2011, 2012), the PV ground systems' diffusion in agricultural fields was less incentive compared to that of integrated installations. This resulted in a turnaround quite marked: nationally, in 2012 , the $43 \%$ of the PV power is installed on the ground, $48 \%$ is placed on buildings, $6 \%$ of greenhouses and shelters and the remaining $3 \%$ is located differently. In 2012 over the previous year, there was 
a reversal of the national weight between ground systems and those integrated that in 2011 were respectively $49 \%$ and $41 \%$ (GSE, 2012).

On the other hand, the use of building covered surfaces to install PV systems involves higher costs because of the expensive support structures required to guarantee adequate ventilation conditions for the partially or totally integrated panels (Huld et al., 2011). Nevertheless, by employing the surface available on the roofs of farm buildings that, according to the estimate of the International Energy Agency (IEA, 2002), amounts to $128 \mathrm{~km}^{2}$ (net space of the overall dimensions) sufficient to produce $16 \mathrm{TWh}_{\mathrm{e}} / \mathrm{year}$ in Italy, the self-sufficiency of agricultural industry would be reached (Brofferio, 2005).

Moreover, it is worthwhile considering another issue related to the sustainable diffusion of PV technology, that is the actual energy efficiency of a PV plant in the future perspective of a farm self-sufficiency. To this purpose, it is necessary to use reliable analytical models (Nofuentes et al., 2003) in order to estimate the energy yield of PV systems. The subject has been widely discussed in scientific literature. Examples can be found in complex simulation models of PV generators, such as those developed by Diez-Mediavilla et al. (2013), Hamad and Alsaad (2010), Alonso-Abella and Chenlo (2004, 2006), Ransome et al. (2002) and Kroposki et al. (1994), in geo-referenced statistical methods for defined geographical areas (Steffen et al., 2013), in simplified procedures for the estimation of energy performance such as those proposed by King et al. (2003) and Abete et al. (2003), or in the evaluation systems using a more intuitive approach (Aguilar et al., 2006).

Even the market of technical and commercial software offers a wide range of products with different degrees of complexity and accuracy based on the application specificity (McEvoy et al., 2012). Currently, the most common modelling and simulation software is photovoltaic geographical information system (PVGIS), developed by the EU Joint Research Center (European Commission, 2012).

In general, the studies that have been carried out and the software available use several algorithms to estimate the energy yield of PV systems, but the uncertainty of some inputs, the partial knowledge of technical data and/or the inaccurate modelling of the plant or one of its components, can somehow reduce the estimation accuracy, which decreases with the increasing of the number of steps and complexity of the PV system model (Ransome, 2007). Indeed, these models provide reliable results only in specific geographical areas. Furthermore, the state-of-the-art reveals the absence of a cross-sectional performance analysis on the potentials offered by the several PV systems (both integrated and ground-mounted) within a well-defined geographical context. Therefore, the aim of this paper is to analyse the impact each plant component has on the global efficiency of a PV generator and define the plant parameters to optimise in order to maximise the annual specific electric energy yield of an architectonically integrated plant installed in a dairy house compared to a ground-mounted plant in the same geographical location.

\section{Materials and methods}

In order to carry out a performance analysis on the potentials offered by the several PV systems (both integrated and ground-mounted), three PV plants have been considered, all of the grid-connected type and installed in the same dairy cattle farm by following three different modalities.

PV plant 1 is installed on the South pitch of a recently built free stabling shed for dairy cattle, in adherence with the surface of the pitch, by following the modality of total architectural integration. PV plant 2 has also followed the model of total integration and is divided into three sub-sections: the pitch of a fixed stabling shed for diary cattle and two pitches of a gable roof barn. On the contrary, PV plant 3 , installed on the ground, has an optimised geometry for the annual activity and occupies a total surface of about 0.8 ha.

In order to estimate the energy yield of these PV systems, an analytical estimation procedure (AEP) has been used following the model proposed in King et al. (2004) and employing: i) the technical specifications of the installed components; ii) the bibliographic values about the estimated energy losses in PV systems (McEvoy et al., 2012; RusCasas et al., 2014); iii) a weather and climate database obtained by collecting the records of the nearest weather station. Moreover, the estimates of energy yield developed by the PGVIS software for the three plants under examination have been also employed and validated for an operating year.

\section{Description of the photovoltaic plants}

The three PV plants form a heterogeneous set from the point of view both of plant design (technology, power conditioning system with DC/AC converter, etc.) and structural characteristics (orientation, support structure, etc.), although all the three systems can be included in the type of fixed axle grid-connected systems. Table 1 summarises their technical specifications.

\section{Analytical estimation procedure of the energy yield of a photovoltaic plant}

Firstly, for each PV plant under examination, an archive of the performances registered in 2012 and two weather and climate databases have been built in order to carry out the analytical procedure for estimating the related electrical performances.

\section{Performance database from photovoltaic generator's monitoring}

The performances, measured at intervals of 10 min on PV1 and PV2 plant meters during 2012, have been calculated in terms of daily cumulative electric energy $\left(E_{R, C}\right)$ and instantaneous power delivered $\left(P_{R}\right)$.

Afterwards, these records have been temporally synchronised, given the several gaps caused by maintenance interventions and unreliable data filtering, while missing data have not been replaced. As for PV plants 1 (except for the period 12-31/12) and 2 (except for the periods 17/08-10/11 and 13-31/12), the hourly average power delivered $\left(\bar{P}_{R}(\mathrm{~h})\right)$ and the electric energy produced $\left(E_{R}(\mathrm{~h})\right)$ have been aggregated on a temporal basis based on the following relations:

$$
\overline{P_{R}}(h)=\frac{1}{6} \sum_{i=0}^{5} P_{R}\left(h+\frac{i}{6}\right) \text { with }\left\{\begin{array}{l}
h=0,1, \ldots, 22,23 \\
\forall P_{R}\left(h+\frac{i}{6}\right)>0
\end{array}\right.
$$

$E_{R}(h)=E_{R, c}(h)-E_{R, c}(h-1)$

As far as PV plant 3 is concerned, only the data on daily electric production were available.

\section{Meteo-climate database}

Given that weather and climate data provided by the monitoring systems of PV plants were not available, the information employed in this analysis came from the Italian regional agency for environmental protection, ARPA (Agenzia Regionale per la Protezione Ambientale) station, which is the nearest to the point of interest, and, by using the Arpa ER Dexter platform, the one with coordinates lat. $44^{\circ} 38^{\prime}$ and long. $10^{\circ} 38^{\prime}$ and $6.1 \mathrm{~km}$ far from PV plants (lat. $44^{\circ} 39^{\prime}$ and long. $10^{\circ} 42^{\prime}$ ) has been chosen.

The weather and climate parameters used are solar irradiation on 
horizontal plane $\left(R_{o}\right)$, air temperature $\left(T_{a}\right)$ and wind speed $(v)$. At the same time, weather and climate data of solar irradiation on tilted and oriented planes, contained in the climate monitoring satellite application facility (CM-SAF) database of PGVIS, have also been employed [Time series of solar irradiation on a tilted and oriented plane, contained in the CM-SAF PVGIS weather database, refer to the average day in a month of the typical solar year and derive from the elaboration of satellite images over a period of 12 years carried out by the CM-SAF collaboration.].

On the other hand, data concerning solar irradiation on horizontal plane, contained in the Arpa archive, have been re-elaborated based on the different PV reception geometries (Coffari, 1977; Parker, 1990) taking solar ephemerides into account (Woolf, 1968; Cooper, 1969). In fact, knowing the global irradiation on horizontal plane, the related normal component on a tilted and oriented surface results:

$$
R_{n}=R_{s} \cdot \sin (90-\beta)=R_{s} \cdot \cos \beta \text { with } R_{s}=\frac{R_{o}}{\sin \varepsilon}
$$

where the normal incidence angle $\beta$, given by the isosceles triangle $\left(P_{1} O P_{2}\right)$, Figure 1, is:

$$
\begin{aligned}
& \overline{P_{1} P_{2}}=\sqrt{\left(x_{1}-x_{2}\right)^{2}+\left(y_{1}-y_{2}\right)^{2}+\left(z_{1}-z_{2}\right)^{2}} \rightarrow \\
& \frac{\overline{P_{1} P_{2}}}{2}=1 \cdot \sin \frac{\beta}{2} \rightarrow \beta=2 \sin ^{-1}\left(\frac{\overline{P_{1} P_{2}}}{2}\right) \\
& \text { with: }
\end{aligned}
$$

$k=1 \cdot \cos (90-\vartheta) ; x_{1}=k \cdot \operatorname{sen} \gamma ; x_{2}=k \cdot \cos \gamma ; z_{1}=\sqrt{1-k^{2}} ;$

$m=1 \cdot \cos \varepsilon ; y_{1}=m \cdot \operatorname{sen} \alpha ; y_{2}=m \cdot \cos \alpha ; z_{2}=\sqrt{1-m^{2}}$

Eq. 3 highlights that during sunrise and sunset, when the sun is very low and PV planes are little tilted, sunrays can hit the panel under the light-sensitive part (because of a problem of temporal synchronisation between Arpa database and that of the actual production), thus originating incorrect $R_{n}$ values. In these cases, non-zero values of measured

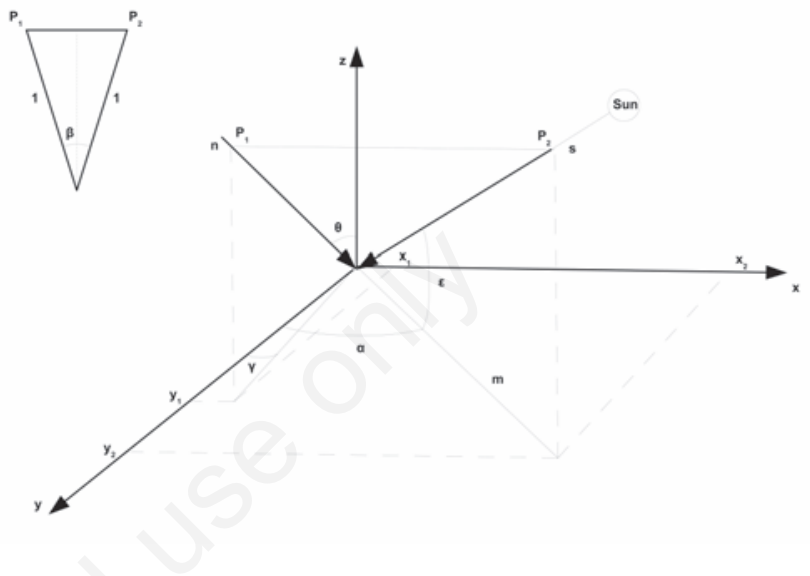

Figure 1. Assessment of normal incidence angle $\beta$.

Table 1. Technical specifications of photovoltaic (PV) plants. As for PV plant 2, sections A, B and C represent, respectively, the Western pitch of the roof of a fixed stabling shed, the Eastern and the Western pitches of a barn roof.

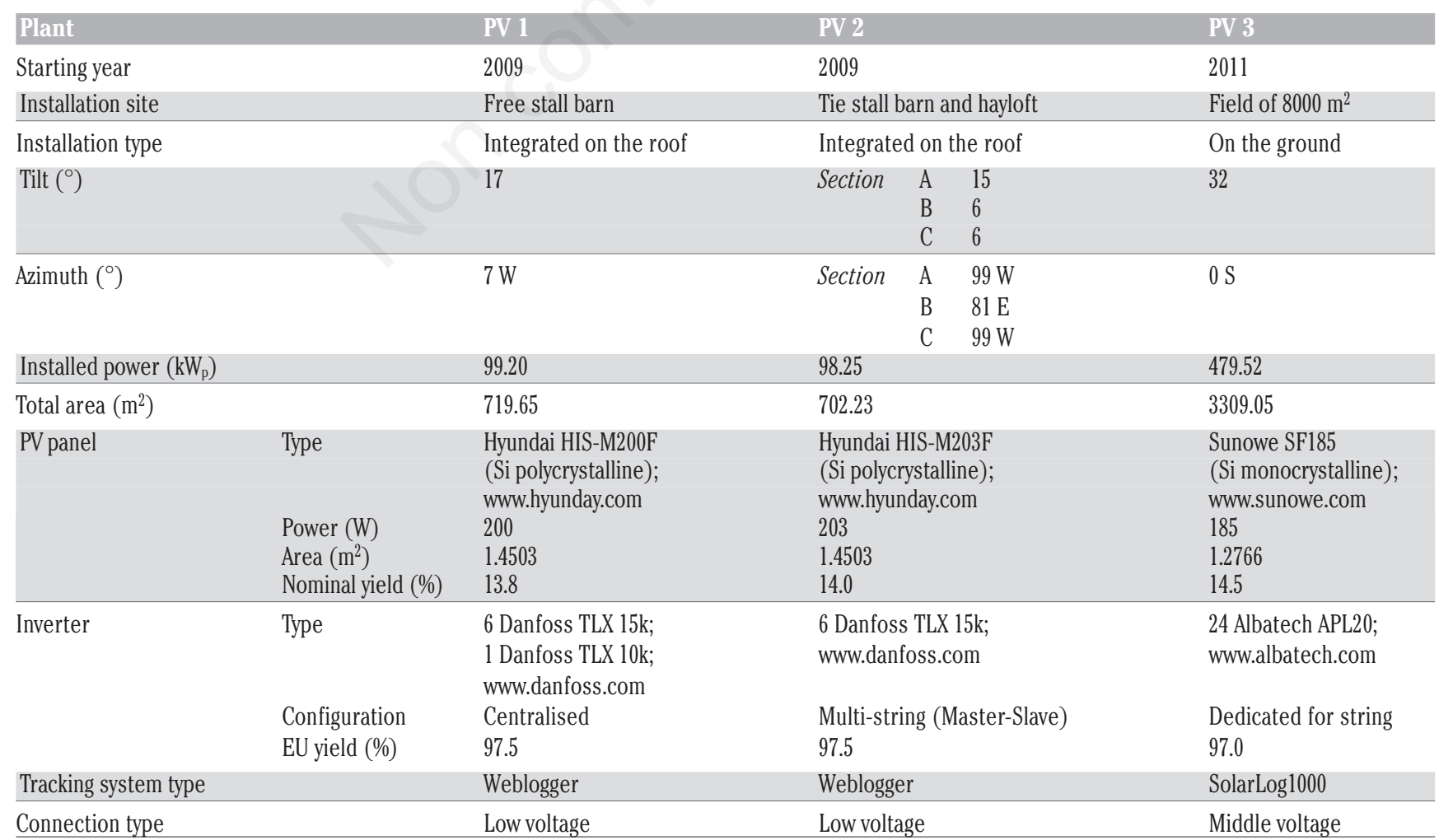


electricity production correspond to zero values of simulated radiation. This condition has been observed, by considering the actual insolation hours in 2012, with the following relative frequency percentages: PV 1, 0.92\%; PV 2-A, 1.45\%; PV 2-B, 0.00\%; PV 2-C, 1.08\%; PV 3, 0.81\%. Therefore the incorrect radiation value has been replaced in accordance with the following:

$$
R_{n}(h)=R_{n}(h-1)-\left[R_{n}(h-2)-R_{n}(h-1)\right]
$$

Given the non-linearity of solar radiation over the time, in order to assess the impact this correction had on the daily production $\left(E_{S, A}\right)$, a sensitivity analysis has been carried out by varying the correct $R_{n}$ value of $\pm 40 \%$. A variance of $\pm 1.6 \%$ in $E_{S, A}$ on the annual average basis is thus obtained for all the PV plants and, for each season, it is equal to: Spring $\pm 0.5 \%$; Summer $\pm 0.4 \%$; Autumn $\pm 1.9 \%$ and Winter $\pm 3.7 \%$. The highest value in Winter is explained by the lower number of insolation hours compared to the summertime.

As for the missing data on normal irradiation $R_{n}$, they have been integrated by averaging the values of the previous and following day at the same time:

$$
R_{n}(h)=\frac{R_{n}(h-24)+R_{n}(h+24)}{2}
$$

\section{Estimation of energy yield}

The theoretical procedure (AEP) proposed, developed in Matlab ${ }^{\circledR}$ environment by following the logical flow chart showed in Figure 2, provides an estimation of the electric energy produced by a PV plant through the following relation (King et al., 2004):
$E_{S}(h)=R_{n}(h) \cdot A \cdot \eta_{S, p}(h) \cdot \eta_{S, B O S}(h)$

with

$E_{S}(h)=R_{n}(h) \cdot A \cdot \eta_{S, p}(h) \cdot \eta_{S, B O S}(h)$

The estimation of $R_{n}$ can be obtained from the Arpa database or PVGIS software. Furthermore, using three large-scale path losses has assessed the energy yield of a PV system: pre-conversion inefficiencies, dissipation in the PV panel and DC/AC power conditioning system before feeding the distribution network. The first loss is ascribable to non-systemic events that cannot be easily assessed (e.g., snow, clouds, dust) and, consequently, it has not been taken into consideration. On the other hand, as for the two remaining losses, the analysis refers separately to the individual components of each PV generator under examination: PV panel and DC/AC power conditioning system.

As far as the PV panel performance $\left(\eta_{S, p}\right)$ is concerned, it varies based on the environmental operating conditions. Hence, the nominal performance, referred to the standard test conditions, has been corrected based on the actual operating conditions. To this purpose, a model proposed by King et al. (2004) has been employed, which considers the impact on the actual performance of PV panel given by the normal irradiation on the surface, the operating temperature and phenomena of reflection.

The performance of a PV panel, similarly to the algorithm of PVGIS software for crystalline silicon panels (Huld et al., 2011), results:

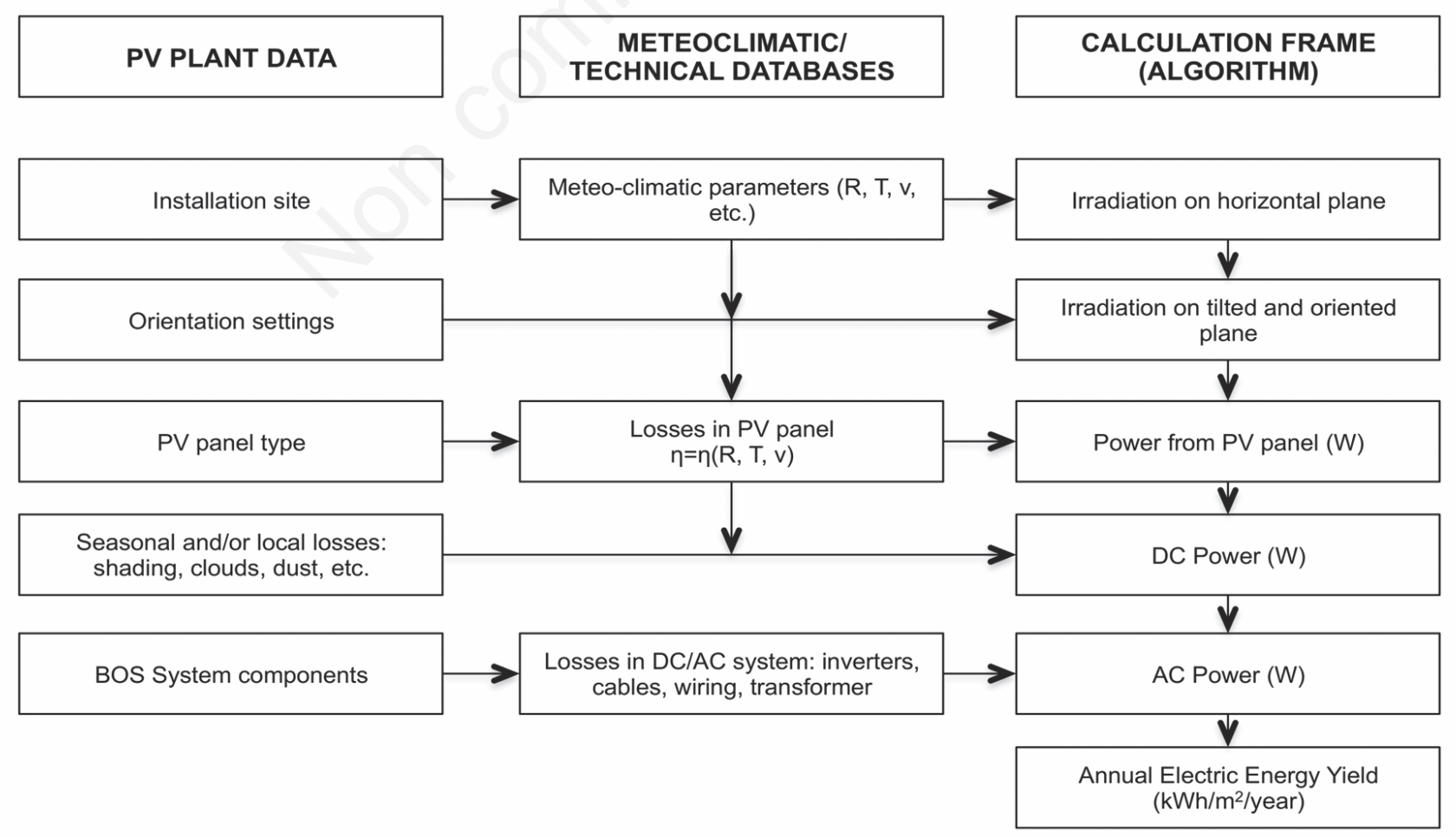

Figure 2. Logical flow chart for the estimation of the energy yield of a photovoltaic (PV) system. 


$$
\begin{aligned}
& \eta_{S, p}(h)=\eta_{N, p} \cdot e f f_{r e l}\left(R_{n}^{\prime}(h), \Delta T(h)\right)= \\
& \eta_{N, p} \cdot\left\{1+k_{1} \cdot \ln \left(R_{n}^{\prime}{ }_{n}(h)\right)+k_{2} \cdot \ln ^{2}\left(R_{n}^{\prime}(h)\right)+\right. \\
& \Delta T(h) \cdot\left[k_{3}+k_{4} \cdot \ln \left(R^{\prime}{ }_{n}(h)\right)+k_{5} \cdot \ln ^{2}\left(R^{\prime}{ }_{n}(h)\right)+\right. \\
& \left.\left.k_{6} \cdot(\Delta T(h))^{2}\right]\right\}
\end{aligned}
$$

where:

$$
R_{n}^{\prime}(h)=R_{n}(h) / 1000, \Delta T(h)=T_{p}(h)-T_{S T C} \text { and } T_{S T C}=25^{\circ} C
$$

The coefficients $k_{i}$, with $i=1, \ldots, 6$, depend on the type of PV technology employed. The values used, taken from the literature (Huld et al., 2010) are related to C-Si panels, Table 2. Moreover, being the panel temperature $\left(T_{p}\right)$ unavailable, the analysis used an empirical model that took into account $T_{a}, R_{n}^{\prime}$ and $v$, the parameters contained in the Arpa database, to estimate the operating thermal regimes of the panel.

Therefore, the hourly temperature of the PV panel is:

$$
T_{p}(h)=0.943 \cdot T_{a}(h)+0.028 \cdot R^{\prime}{ }_{n}(h)-1.528 \cdot v(h)+4.3
$$

Eq. 10 can be applied both for ground-mounted and roof-top architectonically integrated PV systems (Skoplaki and Palyvos, 2009), and it differs from the model implemented in PVGIS for the latter considers only the impact of irradiation on the panel temperature, without accounting for the cooling effect of wind. Finally, as for PV plant 2 , given the presence of three sections with different orientations, Eq. 9 has been calculated as weighted average of the performances of the three collectors actually in place that have been weighted on the corresponding surfaces.

To calculate the $\left(\eta_{S, B O S}\right)$ efficiency of the DC/AC (balance of system, BOS) power conditioning system, the following loss factors have been considered on the basis of Eq. 8:

$\eta_{v}$ : system technical obsolescence and losses caused by the non-uniformity in the operation of modules, strings or the whole PV field, with an annual loss up to $3 \%$ (Rus-Casas et al., 2014). The values employed for the plants under examination, given the corresponding starting times (Table 1) and considering also the losses caused by phenomena of reflection with a decrease in the annual efficiency of $0.6 \div 1.5 \%$ (McEvoy et al., 2012), are: PV plants 1 and 2: 94\%; PV plant 3: $97 \%$;

$\eta_{t}$ : voltage transformer losses occurred downstream of a PV system and measured in a single system performance on an annual average basis equal to $98.5 \%$ (value declared by the network service provider);

$\eta_{c}$ : ohmic dissipation in wiring/cables upstream (DC) or downstream (AC) of the inverter measured in a single system performance on an annual average basis equals to $97 \%$, for each system and each year under examination (Rus-Casas et al., 2014); $\eta_{i}$ : losses due to the inverter operation depending on the variance in the workload compared to the maximum power point. In effect, the higher is the load, the more increases.

Based on their technical specifications, a nonlinear regression analysis has been carried out for PV plants 1 and 2 in order to provide automatically all the possible values:

$$
\eta_{i}(h)=a-b \cdot e^{-c \cdot C(h)}
$$

with $C(h)=\left[P_{R}(\mathrm{~h}) / P_{N}\right] \times 100$, the hour workload percentage of the inverter with relative nominal power $P_{N}$ in $\mathrm{kW}$. Using as coefficients $a$ $=0.97915 ; b=0.07567 ; c=0.09923$, the result obtained is $R^{2}=0.992$, with a maximum percentage error of $0.22 \%$ (Figure 3 ). On the other hand, in the case of PV plant 3, given that data on the actual power delivered are not available (see Section Description of the photovoltaic plants), the performance declared by the manufacturer for the related inverter has been used, which is equal to $97 \%$ with a nominal voltage of 700 Volt in each string.

\section{Comparative analysis between actual and estimated electric performances (analytical estimation procedure and photovoltaic geographical information system)}

The estimation of producible electric energy by the PV plants has been carried out by considering two different estimation models (AEP and PVGIS). The electric production, estimated by using AEP on the basis of Arpa irradiation database $\left(E_{S, A}\right)$, has been calculated by applying Eq. 7, with $R_{n}(h)=R_{A, n}(h)$, to the hours of actual irradiation in the period under examination and considering the conversion losses based on Eq. 8. On the contrary, the electric production estimated according

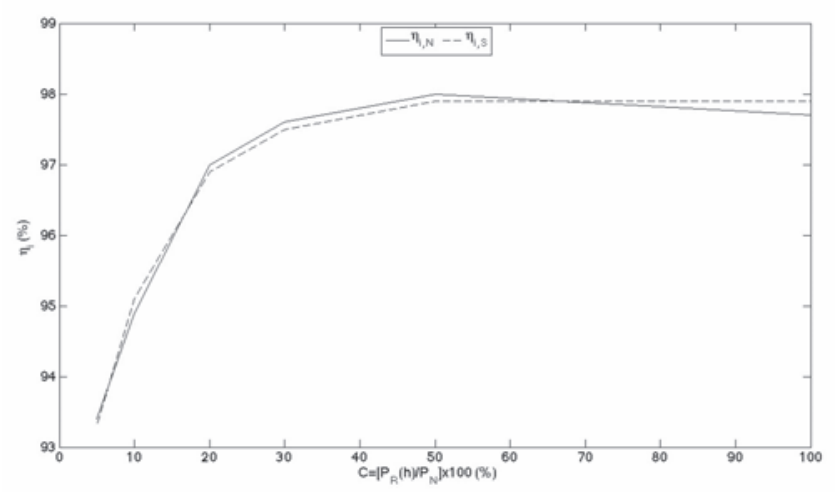

Figure 3. Estimated inverter performance on the basis of the hour workload (Danfoss TLX15; www.danfoss.com).

Table 2. Coefficients for the estimation of a photovoltaic (PV) panel performance based on its technology.

\begin{tabular}{lcccccc}
\hline PV technology & $k_{1}$ & $k_{2}$ & $k_{3}\left[{ }^{\circ} \mathrm{C}^{-1}\right]$ & $k_{4}\left[{ }^{\circ} \mathrm{C}^{-1}\right]$ & $k_{5}\left[{ }^{\circ} \mathrm{C}^{-1}\right]$ & $k_{6}\left[{ }^{\circ} \mathrm{C}^{-1}\right]$ \\
$C$-Si & -0.001716 & -0.040289 & -0.004681 & 0.000148 & 0.000169 & 0.000005 \\
$C I S$ & -0.005521 & -0.038492 & -0.037010 & -0.000899 & -0.001248 & 0.000001 \\
\hline CdTe & -0.103251 & -0.040446 & -0.001667 & -0.002075 & -0.001445 & -0.000023 \\
\hline
\end{tabular}


to PVGIS $\left(E_{S, P}\right)$ has been directly employed, with the exception of PV plant 2 for which the productions of the individual sub-fields have been determined on the basis of the related geometries, along with the total electric energy. The results obtained, for the producible electric energy, have been compared in their aggregated forms for the year available, thus determining monthly and yearly variances between the actual and the estimated production for each plant by following the two-abovementioned modalities. Therefore, in order to make the results comparable, the deviation between the electric productions estimated by each model and the actual electric yield has been calculated, by employing the following equation:

$$
\lambda=\frac{E_{S}-E_{R}}{E_{R}}
$$

Eq. 12 has been assessed both on a monthly and yearly basis so that possible periodicities in the estimates given by each estimation model on the energy yield of PV plants under examination could be evaluated (Miller and Lumby, 2012).

\section{Results and discussion}

\section{Energy yields recorded in 2012}

Energy yields recorded in 2012 were equal to 109.6 MWh, 76.2 MWh and 694.3 MWh for PV plants 1, 2 and 3, respectively (Table 3). As far as PV plant 2 is concerned, the result is only partial (see Section Performance database from photovoltaic generator's monitoring). In terms of electric energy per day and per square meter of light-sensitive surface, the ground-mounted system showed an average production $27 \%$ higher than integrated solutions. However, during the year considerable fluctuations have been reported in the performances of the three systems due to the alternation of seasons and environmental operating conditions, especially in April (Figure 4). The months reporting the highest and the lowest electric production for all the plants were July and December, respectively, corresponding to the periods of maximum and minimum solar radiation during the year. Furthermore, the latter, except for the two-month period of September/October, produced different amounts of electric energy though being of equal powers (Figure 4) with the PV plant 2 resulting more penalised by its complex plant configuration and the orientation of its several sections compared to PV plant 1 . The seasonal comparison shows that PV plant 3 was the most productive in Winter thanks to its better reception geometry $\left(0.35 \mathrm{kWh} / \mathrm{m}^{2} /\right.$ day); while, among the roof-top integrated systems, PV plant 1 produced approximately twice the amount of PV plant 2 because of the layers of snow and ice formed on sections $B$ and $C$ of the barn, which were almost horizontal. In the summertime, PV plant 3, though remaining the most efficient thanks to the better ventilation offered by ground mounting system, reported the lowest inter-seasonal (Winter-Summer) increase in the electric production $\left(+0.48 \mathrm{kWh} / \mathrm{m}^{2} /\right.$ day $)$ due to the sub-optimal tilt of panels during summer. On the other hand, PV plants 1 and 2 showed higher inter-seasonal increases (+0.50 and $+0.49 \mathrm{kWh} / \mathrm{m}^{2} /$ day, respectively).

\section{Estimation of the producible electric energy by photo- voltaic plants}

The following sections report and discuss the results of the estimation of the producible electric energy in accordance with the AEP by applying Arpa insolation data to estimate $\left(R_{n}\right)$, and by examining also the estimated performances of the individual components in each PV system.

\section{Solar energy availability on the installation site}

Table 4 highlights the results obtained for the annual availability of energy received from each PV plant and/or sections as a function of their orientation.

The best orientation is that of PV plant 3 with an increase of solar energy received, compared to the horizontal position, ranging from $23.5 \%$, following Arpa data, to $16.5 \%$ based on the data contained in PVGIS.

The condition of PV plant 1, given the high tilt of its pitched roof, shows also a higher amount of solar energy received, compared to the horizontal position; an increase of $12 \%$ according to PVGIS data and of 18\% based on Arpa measurements have been assessed.

On the contrary, the comparison between PV plant 1 and PV section 2-A (Table 1), highlights that the first produces an increase in the energy receivable which is $14 \%$ higher than the latter although they are branded by similar values of Tilt angle.

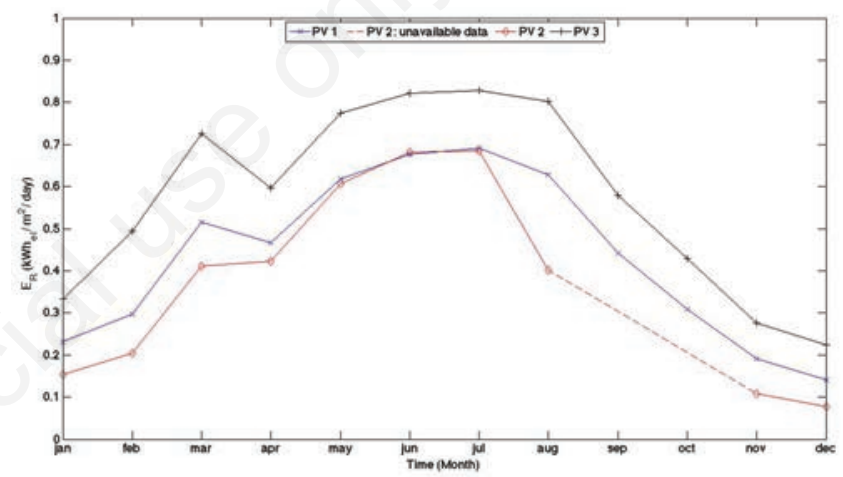

Figure 4. Monthly average electric productions per day and per square meter of photovoltaic (PV) surfaces reported in 2012.

Table 3. Actual electric productions reported in 2012.

\begin{tabular}{lcc} 
Plant & $E_{R}$ & $E_{R}(\mathrm{~d}) \mathrm{m}$ \\
& $(\mathrm{MW} / \mathrm{k} /$ year $)$ & 0.458 \\
PV 1 & 109.6 & 0.446 \\
PV 2 & 76.2 & 0.574 \\
\hline PV 3 & 694.3 &
\end{tabular}

PV, photovoltaic.

Table 4. Annual average daily availabilities of solar energy as a function of photovoltaic (PV) panels' orientation against a horizontal plane.

\begin{tabular}{lccc} 
Plant/section & $\begin{array}{c}\text { Arpa database } \\
\text { (kWh/m²/day) }\end{array}$ & $\begin{array}{c}\text { CM-SAF-PVGIS } \\
\text { (kWh/m²/day) }\end{array}$ \\
PV 1 & 4.497 & 4.501 \\
PV2 & A & 3.932 & 3.878 \\
& B & 3.941 & 4.045 \\
& C & 3.884 & 3.981 \\
\hline PV 3 & & 4.702 & 4.685 \\
\multicolumn{2}{l}{ Horizontal plane } & 3.809 & 4.028 \\
\hline
\end{tabular}

CM-SAF, climate monitoring satellite application facility; PVGIS, photovoltaic geographical information system. 
Indeed, in unidirectional plants (e.g., mono-pitched roof integrated or ground-mounted), a high Tilt angle engenders an increase in the solar energy receivable compared to the horizontal condition only if the Azimuth angle is close to zero (South); while the effect is overturned with East-West orientations (Liberati and Zappavigna, 2012).

On the contrary, for PV systems integrated on gable roofs, the model provided by Liberati and Zappavigna (2012) proposes, for every orientation, a minimum Tilt angle so that all the available surface can be exploited. In fact, in the case of PV sections 2-B and 2-C, that are almost plane, the variances in the solar energy receivable compared to the horizontal condition are minimal $(+1.5 \%$ and $+0.1 \%$, on average according to both databases, Table 4).

\section{Performances of photovoltaic panel}

PV plant 3 panel offered the best performance throughout 2012 (Figure 5A) thanks to the monocrystalline silicon technology and the better cooling condition during summertime given by the ground mounting system (Miller and Lumby, 2012). Among the roof-integrated collectors, PV plant 2 panel showed the lowest efficiency during Autumn and Winter. On the other hand, PV plant 1 panel occupied an intermediate position thanks to its good orientation, especially in Autumn and Winter, while in Summer it resulted insufficiently cooled based on the estimation given by Eq. 10 .

These observations have been also upheld by a detailed performance analysis carried out on a sample of four weeks within the year under examination (Table 5). In effect, in Spring and Winter, the estimated performances of PV 1 and 3 panels reported average values which were not excessively reduced compared to their nominal values; while higher deviations compared to the potentials declared by the manufacturer - with decreases up to $16 \%$ - have been reported in Summer and Autumn.

The estimated performance of PV 2 panel settled on values typical of warm periods (a decrease of approximately 16.8\% in the efficiency caused by heating up to $70^{\circ} \mathrm{C}$ ); while, both in Autumn and Winter, it showed rather low efficiencies probably caused by two concurrent phenomena: an higher diffuse radiation component, typical of Winter, for it has been amplified in case of nearly plane surfaces (e.g., sections 2$\mathrm{B}$ and 2-C), which can produce a greater winter heating of the PV panel.

\section{Performances of DC/AC power conditioning systems}

The estimated annual losses in the power conditioning systems of PV plants ranged between $10 \%$ and $17 \%$, thus confirming the typical performance of this block system (BOS), equal to $80 \div 90 \%$, predicted for grid-connected PV systems (Diez-Mediavilla et al., 2013). In fact, Figure $5 \mathrm{~B}$ shows that the performance of the DC/AC conditioning system in the PV plant 3 is constantly settled on these performance levels for it has been assessed on an annual average basis (see Section Estimation of energy yield).

On the contrary, the trends of performances $\eta_{S, B O S}$ related to PV plants 1 and 2 show a certain periodicity: from April to August, when about the $70 \%$ of the annual electricity is produced, the performances $\eta_{S, B O S}$ are equal, on average, to $84 \%$ thanks to the constant irradiation on panels, and thus having a higher workload of inverters; while, in the remaning part of 2012, performances resulted equal to $82.5 \%$ for PV plant 2 and $83 \%$ for PV plant 1, although these generators had the same inverters (Table 1). The difference could come from the higher operational continuity of PV plant 1 which was guaranteed by the high pitch that facilitated the removal of snow layers from the panels compared to PV sections 2-B and 2-C that were nearly horizontal.

Furthermore, comparing the annual average performances of DC/AC conditioning systems of PV plant 3 to those of PV plants 1 and 2, reported above, a greater efficiency of the former (ground-mounted) can be observed, and on average $6.5 \%$ higher than those estimated for integrated installations. However, this is due to: i) a higher obsolescence
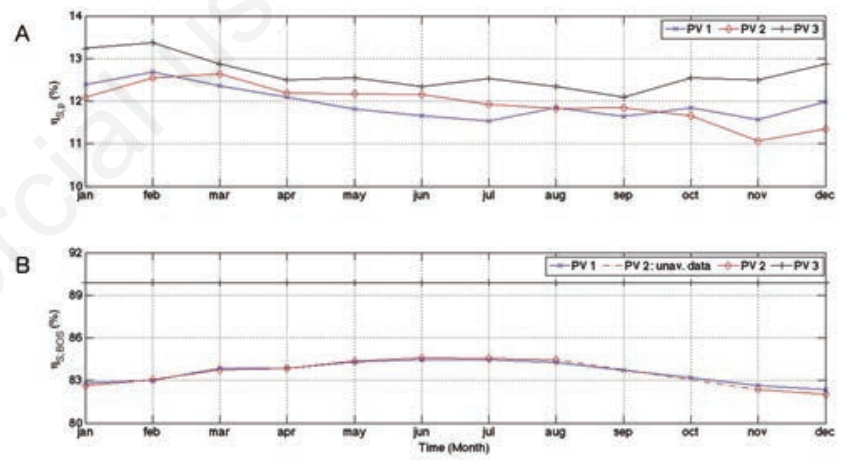

Figure 5. Annual trends of monthly average performances estimated for photovoltaic (PV) panels (A) and DC/AC power conditioning systems (B), by applying the analytical estimation procedure on Arpa insolation data during 2012.

Table 5. Going from left to right, the following values, for each photovoltaic panels and for every sample periods of 2012, are reported: minimum, mean and maximum hourly values for estimated yields; percentage differences between hourly mean estimated yields and nominal ones.

\begin{tabular}{|c|c|c|c|c|c|}
\hline Plant & Week & Min & $\begin{array}{c}\eta_{p s}(\%) \\
\text { Mean }\end{array}$ & Max & {$\left[\left(\eta_{p s}-\eta_{p N}\right) / \eta_{p N}\right] \cdot 100 \%$} \\
\hline PV 1 & $\begin{array}{l}01 / 01-07 / 01 \\
10 / 03-16 / 03 \\
21 / 06-27 / 06 \\
01 / 12-07 / 12\end{array}$ & $\begin{array}{l}3.5 \\
1.5 \\
6.2 \\
1.4\end{array}$ & $\begin{array}{l}12.4 \\
12.5 \\
11.6 \\
11.6\end{array}$ & $\begin{array}{l}13.9 \\
13.7 \\
12.6 \\
13.9\end{array}$ & $\begin{array}{l}-10.1 \\
-9.4 \\
-15.9 \\
-15.9\end{array}$ \\
\hline PV 2 & $\begin{array}{l}01 / 01-07 / 01 \\
10 / 03-16 / 03 \\
21 / 06-27 / 06 \\
01 / 12-07 / 12\end{array}$ & $\begin{array}{l}1.2 \\
1.1 \\
2.8 \\
1.1 \\
\end{array}$ & $\begin{array}{c}10.5 \\
11.7 \\
11.6 \\
9.9\end{array}$ & $\begin{array}{l}14.1 \\
13.8 \\
12.8 \\
13.9\end{array}$ & $\begin{array}{l}-25.0 \\
-16.4 \\
-17.1 \\
-29.3\end{array}$ \\
\hline PV 3* & $\begin{array}{l}01 / 01-07 / 01 \\
10 / 03-16 / 03 \\
21 / 06-27 / 06 \\
01 / 12-07 / 12\end{array}$ & $\begin{array}{c}2.8 \\
12.6 \\
12.4 \\
7.9\end{array}$ & $\begin{array}{l}13.3 \\
13.0 \\
12.5 \\
12.3 \\
\end{array}$ & $\begin{array}{l}14.1 \\
13.9 \\
12.7 \\
13.8\end{array}$ & $\begin{array}{c}-8.3 \\
-11.1 \\
-13.8 \\
-12.4 \\
\end{array}$ \\
\hline
\end{tabular}

PV, photovoltaic. *Data assessed on average daily basis. 
rate of PV plants 1 and 2 (2 years older): every operating year it produced a decrease of $0.6 \div 1.5 \%$ in the global performance of the system (McEvoy et al., 2012) with a partial contribution in $\eta_{S, B O S}$ of $2 \div 2.5 \%$; ii) the nominal performance considered for the inverter of PV plant 3 (see Section Estimation of energy yield): this assumption has effectively generated a value of $\eta_{S, B O S}$ for PV plant 3 higher than 4\% compared to the estimates of PV 1 and 2 thus integrating the annual average difference previously observed.

\section{Comparative analysis of the estimated electric yields by employing analytical estimation procedure and photovoltaic geographical information system}

The estimates of annual electric yields and energetic efficiencies globally and for the individual components of each PV plant - obtained by employing the AEP procedure, have been compared as aggregates with those provided by PVGIS software in the available year. The analysis was divided into two stages: firstly, the annual losses estimated in accordance with the abovementioned procedures have been compared and, afterwards, the estimates of electric yields have been validated against the actual productions reported for each PV plant.

\section{Conversion losses estimated in the operating year}

Table 6 shows the annual losses based on the AEP procedure applied to Arpa meteo-climatic data and those provided by PVGIS software for the three PV plants.

The estimates calculated by applying the AEP to Arpa data and those provided by PVGIS are sufficiently concordant in the case of PV plant 1; while, for PV plants 2 and 3, the first estimation exceeds the second of $1.72 \%$ and $3.19 \%$, respectively, even though the algorithm of PVGIS did not consider directly the effect of the wind (Skoplaki and Palyvos, 2009). These moderate deviations have been caused by an overestimation of the Summer mean temperatures of the panels, measured in the reference year, given by Eq. 10 compared to the estimates provided by PVGIS (lower than 14\% and 17\% compared to the former). In effect, through the implementation of the analytical model contained in PVGIS, summer thermal dissipations have been estimated to be lower than 1.22\% (PV 1), 1.81\% (PV 2) and 0.84\% (PV 3) compared to those provided by Eq. 10; while, on an annual basis, these deviations have been equal to $0.61 \%, 0.85 \%$ and $0.45 \%$, respectively.

Therefore, this comparison has again confirmed a high concordance between the two estimation models in the case of roof-integrated plants but, in the case of the ground-mounted PV plant 3, a deviation of $2.7 \%$ (Table 6 ) has been reported that can be justified only by the more intense cooling estimated by PVGIS during Summer. As for the losses in the DC/AC (BOS) power conditioning system, the estimates provided by the two models are sufficiently concordant in the case of PV plants 1 and 2 , showing a deviation of $\pm 0.40 \%$ (Table 6 ). On the other hand, as for PV plant 3, PVGIS estimated a greater loss in the system, approximately higher than $6 \%$ compared to that provided by the AEP applied on Arpa data. The causes of this difference can be attributed to what has already observed in paragraph Performances of DC/AC power conditioning systems. Nevertheless, it is worthwhile noting that PV plant 3 does not show levels of global efficiency much higher than those reported for PV plants 1 and 2, according to both estimation models. In fact, by comparing PV plants 3 and 1, the estimated variance in the global loss between the two PV generators ranges from $3.1 \%$ to $3.7 \%$. Consequently, roof-integrated PV systems, if well dimensioned, can reach levels of global efficiency virtually close to those of groundmounted systems; on the contrary, the systems integrated on more than one pitched roof show losses that are at least higher than $1 \div 2 \%$ caused by the different operating conditions in each light-sensitive section and/or subfield as in the case of PV plant 2.

\section{Validation of electric yields estimated by analytical estimation procedure on Arpa data and photovoltaic geographical information system}

The estimates provided both by AEP on Arpa data and PVGIS show that the best annual performance in terms of specific electric energy is always given by $\mathrm{PV}$ plant 3 because it guarantees an electric production from $6 \%$ to $12 \%$ higher than those provided by integrated PV plants 1 and 2 (Table 7).

On the contrary, the latter, when compared throughout the year, except for the months of September and October (Figure 6), show lower actual electric productions compared to the several estimates provided. For the

Table 6. Annual losses based on the analytical estimation procedure applied to Arpa meteo-climatic data and those provided by photovoltaic geographical information software for photovoltaic plants 1,2 (values averaged on the three sections) and 3 .

\begin{tabular}{|c|c|c|c|c|c|c|}
\hline $\begin{array}{l}\text { Plant } \\
\text { Energy losses } \\
\text { (\%Convertible solar energy) }\end{array}$ & $\begin{array}{l}\text { AEP on } \\
\text { Arpa data }\end{array}$ & PVGIS & $\begin{array}{l}\text { AEP on } \\
\text { Arpa data }\end{array}$ & PVGIS & $\begin{array}{c}\text { AEP on } \\
\text { Arpa data }\end{array}$ & PVGIS \\
\hline Panel (temperature, low irradiation, etc.) & 13.42 & 13.70 & 14.61 & 12.89 & 12.79 & 9.60 \\
\hline $\begin{array}{l}\text { BOS (inverter, cables, wiring, } \\
\text { reflection phenomena, etc.) }\end{array}$ & 16.37 & 16.00 & 16.47 & 16.88 & 10.09 & 16.30 \\
\hline Total & 27.60 & 27.20 & 28.67 & 27.20 & 23.94 & 24.10 \\
\hline
\end{tabular}

PV, photovoltaic; AEP, analytical estimation procedure; PVGIS, photovoltaic geographical information system; BOS, block system.

Table 7. In the order starting from left to right, for each photovoltaic (PV) plant and by applying the analytical estimation procedure on Arpa meteo-climatic data and the photovoltaic geographical information system, the following data are reported: estimated annual and daily electric energy per square meter; solar energy gain against a horizontal plane; global efficiency, considering also the impact of PV technology.

\begin{tabular}{|c|c|c|c|c|c|c|c|c|}
\hline Plant & & AEF & on Arpa data & & & & PVGIS & \\
\hline & $\begin{array}{c}\mathrm{E}_{\mathrm{S}, \mathrm{A}} \\
(\mathrm{MWh} / \mathrm{year})\end{array}$ & $\begin{array}{c}E_{\mathrm{S}, \mathrm{A}}(\mathrm{d}) \\
\left(\mathrm{kWh} / \mathrm{m}^{2} / \mathrm{day}\right)\end{array}$ & $\begin{array}{l}\text { Solar energy gain } \\
\text { (\%Horizontal plane) }\end{array}$ & $\begin{array}{l}\text { Total system } \\
\text { efficiency ( } \%)\end{array}$ & $\begin{array}{c}\mathrm{E}_{\mathrm{S}, \mathrm{A}} \\
(\mathrm{MWh} / \text { year) }\end{array}$ & $\begin{array}{c}\bar{E}_{\mathrm{S}, \mathrm{A}}(\mathrm{d}) \\
\left(\mathrm{kWh} / \mathrm{m}^{2} / \mathrm{day}\right)\end{array}$ & $\begin{array}{l}\text { Solar energy gain } \\
\text { (\%Horizontal plane) }\end{array}$ & $\begin{array}{l}\text { Total system } \\
\text { efficiency (\%) }\end{array}$ \\
\hline PV 1 & 121.7 & 0.509 & +18.06 & 76.21 & 112.1 & 0.470 & +11.74 & 76.55 \\
\hline PV 2* & 84.9 & 0.497 & +2.88 & 75.34 & 77.6 & 0.455 & +1.49 & 76.61 \\
\hline PV 3 & 675.1 & 0.560 & +23.44 & 79.53 & 620.1 & 0.493 & +16.31 & 79.39 \\
\hline
\end{tabular}

AEP, analytical estimation procedure; PVGIS, photovoltaic geographical information system. *Averaged values on the three sections. 
possible causes see Section Energy yields recorded in 2012.

However, PV plant 1, though having a power equal to PV plant 2, shows a larger production compared to the latter, on the basis of both the actual electric yields and the estimates provided by the two models, thanks to the better orientation of its panels and configuration of its DC/AC conditioning system.

PV plant 3 also shows, according to the several estimates, the lowest inter-seasonal Winter-Summer increase among the PV systems under examination: +0.383 and $+0.442 \mathrm{kWh} / \mathrm{m}^{2} /$ day for AEP and PVGIS, respectively, because of an excessive tilt during summertime.

The same increase, estimated for PV plants 1 and 2 and by applying each estimation model, shows values that are in line with the actual ones reported in Section Energy yields recorded in 2012.

Hence, it can be concluded that - although PV plant 3 was the most productive during the year under examination thanks to its ideal orientation for the annual operations and to the best ventilation it was provided during Summer - integrated PV plants 1 and 2 can also reach, in theory, competitive levels of electric production per square meter (Table 7).

However, in the light of the analysis carried out on the actual performances (see Section Energy yields recorded in 2012), the deviation between the electric yield of PV plant 3 and the average yields of integrated PV plants 1 and 2 showed to be approximately of $27 \%$.

Consequently, an error, ranging from 15\% (AEP) to 21\% (PVGIS), is reported in the estimation of the annual loss of electric yield in the passage from ground-mounted to architectonically integrated plants.

In fact, by assessing the coincidence between the estimated and the actual electric productions for each system (Table 8), it can be noted that the AEP on Arpa data produced an overestimation in the case of PV plants 1 and 2, which was equal to $11.25 \%$ on average; while the estimation was more accurate in the case of PV plant 3 (rounded down by $2.76 \%)$. On the contrary, PVGIS software provided more accurate estimates for PV plants 1 and 2, while those of PV 3 were strongly underestimated (10.60\%). These deviations between the estimated and actual electric yields reveal to be even more evident when analysing the monthly trends of the parameter $\lambda_{R, S}$. In effect, for every estimation model and each PV system under examination, the monthly maximum and minimum values for the parameter $\lambda_{R, S}$ were reported in Winter and Autumn (Figure 7) due to the higher variability in the local insolation conditions and, thus, in the operation conditions of PV generators during these periods.

On the contrary, in Summer, $\lambda_{R, S}$ assessed for both models, reported more limited monthly absolute values thanks to more stable environmental operating conditions, except for PV plant 3 whose actual summer production was at least $10 \%$ higher than all the estimates reported, probably because, as already said, of a better actual cooling of groundmounted panels.

On the contrary, the estimates of global losses seem to be sufficiently concordant for each PV plant (see Section Solar energy availability on the installation site). Therefore, a general uncertainty can be noted in the estimation of the electric yields of the three PV plants during the year under examination due to pre-conversion losses.

The existence of variability factors in solar intensity, not included in the two models, has actually generated deviations between the estimated and actual electric yields in absolute values in the range of $1.91 \div 11.43 \%$, that should be considered acceptable for the adoption of climatic data detected far from the installation site can imply an error up to $6 \%$ (Ransome et al., 2002; Ransome, 2007). However, these deviations should be assessed over the whole technical lifetime of the plant in order to consider also the errors in the long-term assessments of a PV system electric yield caused by the inter-annual variability of insolation and conversion losses (Miller and Lumby, 2012).

\section{Main technical parameters for maximising the electric yield of a photovoltaic plant}

The comparison between the ground-mounted PV plant 3 and the integrated PV plants 1 and 2 highlights that the PV field orientation defined by the Tilt and Azimuth angles -, rather than by the performances of the panel or DC/AC conditioning system, allows to maximase the theoretical annual specific electric yield provided by a PV plant.

However, the orientation of a PV plant integrated on the roof of a dairy barn is affected by other technical aspects such as the maintenance of internal meteoclimatic conditions which prevent any form of heat stress for the animals housed therein (Zappavigna and Liberati, 2002). In fact, this may lead to a reduction of milk production especially for those dairy cows reared in warm and humid climates like the Mediterranean (Shoshani and Hetzroni, 2013). Therefore, in order to maximise the natural ventilation inside the building (stack effect in Winter and wind effect in Summer), the barn should be oriented with the longitudinal axis along the west-east direction with a slope roof between 14 and 20 degrees (Ferrari et al., 2006). On the contrary, the optimisation of a PV system orientation can result both in the maximisation of the solar energy receivable and convertible in electricity (Liberati and Zappavigna, 2012) and in the passive reduction of the

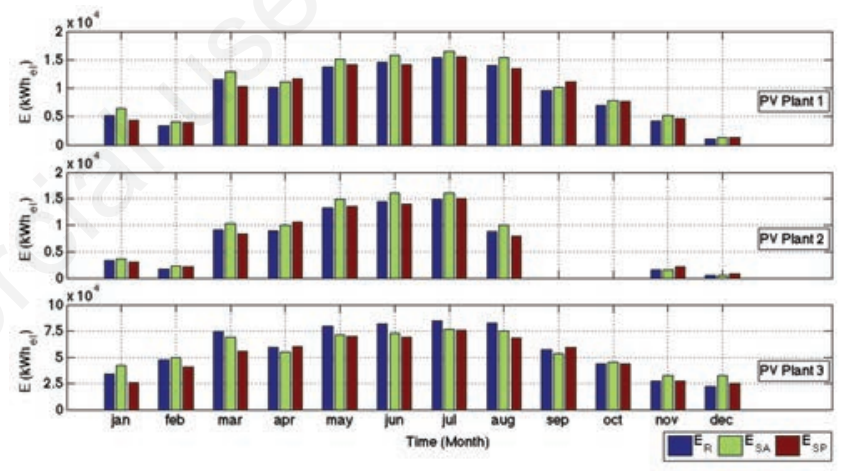

Figure 6. Actual electric productions (blue), estimated by employing the analytical estimation procedure on Arpa weather and climate data (green) and photovoltaic geographical information system data (red), of photovoltaic (PV) plants 1, 2 and 3 in 2012.

A

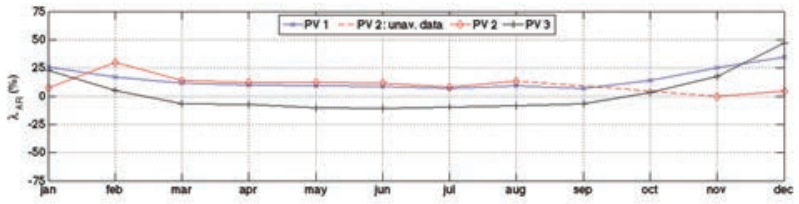

B

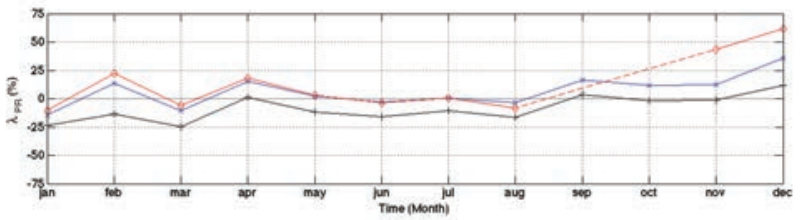

Figure 7. Trends of the monthly mean deviations $(\lambda)$ between actual and estimated electric productions calculated by employing analytical estimation procedure on Arpa data (A) and the photovoltaic geographical information software $(B)$, related to photovoltaic (PV) plants 1, 2 and 3 in 2012. 
shielding effect caused by possible deposits on the panels (McEvoy et al., 2012), considering also the need of automatic cleaning systems. Generally, for the northern Italy latitude, a PV system optimised for the annual operating is characterised by a value of the Tilt angle between 30 and 35 degrees, and a zero angle of Azimuth as in the case of the PV 3. Thus, a well-oriented livestock building, from the point of view of the internal microclimatic control, has a value of the Tilt angle (or slope roof) lower than the optimal inclination for maximising the solar radiation collection, but, as regards the Azimuth angle, the two optimal conditions lead to the same result (South orientation). Nevertheless, by examining Table 7 , it can be observed that the estimates obtained both by AEP and PVGIS software report, on one hand, annual levels of conversion loss that are similar for all the PV generators (including also the effect of PV technology) and, on the other hand, a higher specific electric yield in the better-placed, better-dimensioned, integrated PV plant 1 compared to PV plant 2.

In the first case, in fact, its almost perfect South orientation and the high tilt of its roof guarantee an increase in the receivable solar energy, compared to the horizontal plane, of only five percentage points lower than that measured in PV plant 3, considering also the reduced variance in the global performances of the two generators (about 3\%). Consequently, it has been reported a deviation, on average, of only 0.04 $\mathrm{kWh} / \mathrm{m}^{2} /$ day in the estimated electric yields of the two systems according to both estimation models. Thus, it is noted that, as in the case of PV 1, a PV plant, integrated on the roof of a barn designed according to current construction standards concerning the internal climatic passive control (Table 1), may be regarded as competitive than a groundmounted system.

In the second case, the partition in several sections of PV plant 2 involves an average availability of solar energy which is definitely lower than that of the ground-mounted PV plant 3 and, finally, a potential electric production lower than $0.05 \mathrm{kWh} / \mathrm{m}^{2} /$ day on average, compared to the latter, to which a greater conversion loss of approximately $4 \%$ is also added (Table 7).

\section{Conclusions}

This paper focused on the comparative performance analysis of three different PV plants installed in the same dairy cattle farm. In this perspective, an AEP has been developed in order to estimate the related electric yields.

The results obtained by employing the AEP have been compared to those provided by the PVGIS software and validated against the actual electric productions of each PV system.

This comparison allowed to assess the impact of the individual plant's component on the global efficiency of different PV generators and to define the main technical parameters for optimising in order to maximise the annual specific electric yield of a roof-integrated system compared to a ground-mounted one in view of a sustainable diffusion of PV technologies in the farming industry.

Firstly, the analysis of actual electric yield recorded in the operating year allowed to establish how the type of installation, the plant components and the operating conditions have influenced the actual performances of the PV systems under examination.

In fact, thanks to its optimal orientation and to the better cooling of ground-mounted panels during summer, the electric energy produced by PV plant 3 was on average $27 \%$ higher than that produced by integrated systems (PV plants 1 and 2).

On the contrary, the better orientation and configuration of the integrated PV plant 1 guaranteed an electric yield per square meter approximately $3 \%$ higher than that of PV plant 2 , which was penalised by its multi-section layout with different orientation.

Secondly, the results given by the two estimation models highlighted a variance in the estimation of electric yield, not higher than $11.5 \%$ considering all the PV plants. This was due to the uncertainty on the actual environmental conditions amplified by the effect of climatic data that were detected far from the installation site or, however, obtained through indirect measurements as in the case of the CM-SAF database, thus implying a decrease in the accuracy up to 6\% (Ransome, 2007).

Consequently, the electric production per square meter, as estimated for the ground-mounted PV plant 3 shows on average an increase ranging from $6 \%$ (PVGIS) to $12 \%$ (AEP) compared to those reported for integrated systems.

From the point of view of global efficiency, PV plant 3 reported electric yields, assessed by both models, of 79.5\%; while those related to roof-integrated systems ranged between $75.9 \%$ (PV plant 2) and 76.4\% (PV plant 1). The difference was caused by: i) the nominal value of the performance panel installed on PV plant 3 , that was $0.7 \%$ higher than that of roof-integrated polycrystalline silicon panels, more suitable to receive diffuse radiation (Huld et al., 2012); ii) the lower dissipation estimated for ground-mounted panels (lower than $2 \div 3 \%$ compared to those of rooftop collectors that were less cooled during summer); iii) the better DC/AC power conditioning system of PV plant 3, with inverters dedicated to each string (on average 3\% more efficient than those evaluated for integrated PV systems, based on AEP and PVGIS models). Furthermore, in the case of multi-field integrated PV system (e.g., PV plant 2), it seems to be crucial the installation of master-slave inversion systems with dedicated inverter for each section, otherwise a further global efficiency decrease could be reported because of a higher operational variability that, based on the AEP developed, results in approximately $1 \%$ of the solar energy virtually convertible.

For these reasons, the main technical parameters for maximising the annual specific electric energy of an architectonically integrated system - compared to a ground-mounted system - have been identified in the Tilt and Azimuth angles of PV panels. In fact, once determined a deviation in the global efficiency ranging from $3 \%$ to $4 \%$ according to the PV generator type - that could be moreover reduced through the implementation of the developed AEP - the optimisation of the PV panels orientation for a given geographical location allows to maximise the annual solar energy receivable and convertible in electricity (for the northern Italy latitude, Tilt and Azimuth angles respectively equal to $30 \div 35^{\circ}$ and $0^{\circ}$ ). Nonetheless, taking into account the typical summer decline in milk production due to the heat-stress suffered by dairy cows reared in humid and warm climates such as the Mediterranean one, the orientation of a PV system integrated in the roof of a stall is influenced by the need to foster natural ventilation within the building (west-east orientation and roof slope between 14 and 20 degrees). Therefore, a well-oriented, barn from the point of view of the internal environmental control, offers a value of the Tilt angle (or slope roof) lower than the optimal inclination for energy yield maximising. On the contrary, as regards the optimal Azimuth angle, the two requirements are fulfilled with the South orientation. However, the PV plant 1, which is installed on the roof of a well-oriented barn from the internal climatic point of view, reported an increase in the solar energy convertible up to $18 \%$ higher than that obtainable on the horizontal plane thanks to the high tilt of the roof and its being oriented almost perfectly to South. In addition, this increase is similar to the one estimated for the ground-mounted PV generator that, given the optimised exposure for the annual operation, resulted to be of $+20 \%$ on average. Therefore, it is noted that a PV plant, integrated on the roof of a barn designed according to current construction standards concerning the internal climatic passive control, may be regarded as competitive than a groundmounted system in terms of annual electric yield per photosensitive square meter. 
Finally, integrated PV systems, besides reaching the same levels of energy efficiency as the ground-mounted systems, are even more sustainable compared to the latter, provided that there is both a suitable orientation and an accurate design, especially to prevent the warming of PV panels during summer, on a surface that is already available and, however, based on the architectural typology of building roofs.

\section{References}

Abete A., Napoli R., Spertino F. 2003. A simulation procedure to predict the monthly energy supplied by grid connected PV systems. Proc. $3^{\text {rd }}$ World Conf. Photovoltaic Energy Conversion. IEEE, Osaka, Japan, 3:2427-30.

Aguilar J.D., Pérez-Higueras P.J., de la Casa J., Rus-Casas C. 2006. Cálculo de la energía generada por un sistema fotovoltaico conectado a la red: aplicación docente. Congreso de Tecnologías Aplicadas a la Enseñanza de la Electrónica TAEE, Madrid, Spain.

Alonso-Abella M., Chenlo F. 2004. A model for energy production estimation of PV grid connected systems based on energetic losses and experimental data. On site diagnosis. pp 2447-50 in $19^{\text {th }}$ Eur. Photovoltaic Solar Energy Conf., Paris, France.

Alonso-Abella M., Chenlo F. 2006. Sistemas fotovoltaicos conectados a red: estimaciòn de la energìa generada [I-II]. Era Solar. 131-2:36$47,52-66$.

Agenzia per la Protezione Ambientale (ARPA) della Regione Emilia Romagna. Sistema Dexter Idro-Meteo-Clima. Available from: http://dexter-smr.arpa.emr.it/Dexter/Login

Bayod-Rùjila A., Ortega-Bielsa A., Martìnez-Garcia A. 2011. Photovoltaics on flat roofs: energy considerations. Energy 36:19962010.

Bianco I., Pascuzzi S., Anifantis S. A., Scarascia-Mugnozza G. 2014. Study of a pilot photovoltaic-electrolyser-fuel cell power system for a geothermal heat pump heated greenhouse and evaluation of the electrolyser efficiency and operational mode. J. Agric. Engine. 45:111-8.

Brofferio S. 2005. Potenzialità, costi e incentivi per l'energia fotovoltaica in Italia. pp 8 in Natl. Conf. Energy Politics in Italy, Conf. Proc., Bologna, Italy.

Castellano S. 2014. Photovoltaic greenhouses: evaluation of shading effect and its influence on agricultural performances. J. Agric. Engine. 45:168-75.

Coffari E. 1977. The sun and the celestial vault. In: A.A.M. Sayigh (ed.), Solar energy engineer. Academic Press, New York, USA.

Cooper P.I. 1969. The absorption of radiation in solar stills. Solar Ener. 12:333-46.

Díez-Mediavilla M., Dieste-Velasco M.I., Rodríguez-A.M.C., García-C.T., Alonso T.T. 2013. Performance of grid-tied PV facilities: a case study based on real data. Ener. Convers. Manage. 76:1396-408.

Frascarelli A., Ciliberti S. 2011. La diffusione del fotovoltaico in Italia e l'impatto sull'agricoltura. Agriregionieuropa, anno 7 n. 24. Available from: http://agriregionieuropa.univpm.it

Ferrari P., Rossi P., Gastaldo A. 2006. Come creare il clima ottimale nella stalla. Inf. Agr. 39:12-6.

European Commission (Joint Research Centre). 2012. Photovoltaic geographical information system (PVGIS). Available from: http://re.jrc.ec.europa.eu/pvgis/index.htm

GSE (Gestore dei Servizi Energetici). 2010. Il solare FV. Dati statistici al 31/12/2009 e totale dei risultati del conto energia. GSE, Roma, Italy.

GSE (Gestore dei Servizi Energetici). 2012. Il solare FV. Rapporto statistico 2012. GSE, Roma, Italy.
Hamad A.A., Alsaad M.A. 2010. A software application for energy flow simulation of a grid connected photovoltaic system. Ener. Convers. Manage. 51:1984-9.

Huld T., Friesen G., Skoczek A., Kenny RP., Sample T., Field M., Dunlop ED. 2011. A power-rating model for crystalline silicon PV modules. Solar Ener. Mater. 95:3359-69.

Huld T., Gottschalg R., Beyer H.G., Topic M. 2010. Mapping the perfomance of PV modules, effects of module type and data averaging. Solar Ener. 84:324-38.

Huld T., Muller R., Gambardella A. 2012. A new solar radiation database for estimating PV performance in Europe and Africa. Solar Ener. 86:1803-15.

IEA (International Energy Agency). 2002. Potential for building integrated photovoltaics. In: Photovoltaic power system program summary. IEA, Paris, France, p 8.

Italian Regulation, 2011. Ministero Dello Sviluppo Economico - Decreto 5 maggio 2011. Incentivazione della produzione di energia elettrica da impianti solari fotovoltaici. (11A06083). In: G.U. Ser. Gen. n. 109, 12/5/2011. Available from: http://www.gazzettaufficiale.it/ eli/id/2011/05/12/11A06083/sg

Italian Regulation, 2012. Decreto-Legge 24 gennaio 2012, n. 1 (Raccolta 2012). Disposizioni urgenti per la concorrenza, lo sviluppo delle infrastrutture e la competitività. (12G0009). In: G.U. Ser. Gen. n. 19, 24/1/2012 - Suppl. Ord. n. 18. Available from: http://www. gazzettaufficiale.it/eli/id/2012/01/24/012G0009/sg

Karkacier 0., Gokalp G.Z., Cicek A. 2006. A regression analysis of the effect of energy use in agriculture. Energy Policy 34:3796-800.

King D.L., Boyson W.E., Kratochvil J.A. 2003. Energy-based performance modeling for photovoltaic systems. pp 131-2. in N.C. for Phovoltaics and Solar Program Review Meeting, Denver, C0, USA.

King D.L., Boyson W.E., Kratochvil J.A. 2004. Photovoltaic array performance model. Sandia report SAND2004-3535. Sandia National Lab., Alburquerque, NM, USA.

Kraatz S., Berg W.E. 2007. Energy demand for milking dairy cows. p 12 in ASABE Annual Int. Meeting, Technical Papers n. 10, Minneapolis, MN, USA.

Kroposki B., Emery K., Myers D., Mrig L. 1994. A comparison of photovoltaic module performance evaluation methodologies for energy ratings. IEEE PV Spec. Conf. 1:858-62.

Liberati P., Zappavigna P. 2012. Evalutation of solar energy on the roofs of livestock houses. J. Agric. Engine. 43:165-9.

McEvoy A.J., Markvart T., Castañer L. 2012. Practical handbook for photovoltaics: fundamentals and applications. Academic Press (Elsevier), Waltham, MA, USA.

Miller A., Lumby B. 2012. Utility scale solar power plants: a guide for developers and investors. Guidilines book written for IFC. World Bank Group, New Delhi, India.

Nofuentes G., Aguilera J., Rus-Casas C., Santiago R.L. 2003. A short assessment on the profitability of PV grid-connected systems using classical investment project analysis. Proc. $3^{\text {rd }}$ World Conf. Photovoltaic Energy Conversion. IEEE, Osaka, Japan, 3:2632-5.

Parker B.F. 1990. Solar energy in agriculture. In: B.A. Stout (ed.), Energy in world agriculture. Elsevier Science Ltd Publishing, Amsterdam, the Netherlands, 4:1-38.

Pelletier N., Audsley E., Brodt S., Garnett T., Henriksson P., Kendall A., Kramer K.J., Murphy D., Nemecek T., Troell M. 2011. Energy intensity of agriculture and food systems. Annu. Rev. Environ. Resour. 36:233-46.

Ransome S.J. 2007. How well do PV modelling algorithms really predict performance?. 22nd European PVSEC, Milano, Italy. Available from: http://steveransome.com/PUBS/2007Milan_4EP_1_1_paper.pdf

Ransome S.J., Woohlgemuth J.H., Poropat S., Morgan R. 2002. $\mathrm{KWh} / \mathrm{kWp}$ dependency on PV technology and balance of systems 
performance. IEEE PV Spec. Conf. 9:1420-3.

Rus-Casas C., Aguilar J.D., Rodrigo P., Almonacid F., Pérez-Higueras P.J. 2014. Classification of methods for annual energy harvesting calculations of photovoltaics generators. Ener. Convers. Manage. 78:527-36.

Shoshani E., Hetzroni A. 2013. Optimal barn characteristics for highyielding Holstein cows as derived by a new heat-stress model. Animal 7:176-82.

Skoplaki E., Palyvos J.A. 2009. Operating temperature of photovoltaic modules: a survey of pertinent correlations. Renew. Ener. 34:23-9.
Steffen R.E., Sung J.S., Yong H.A., Ford G. 2013. Modeling energy generation by grid connected photovoltaic systems in the United States. J. Build. Constr. Plan. Res. 1:39-44.

Woolf H.M. 1968. On the computation of solar elevation angles and the determination of sunrise and sunset times. National Aeronautics and Space A. Report NASA TM-X-164.

Zappavigna P., Liberati P. 2002. Thermal behaviour of animal houses in hot climate: experimental approaches to the theoretical approach. Paper no. 024110. pp 1-10 in ASAE Ann. Int. Meeting, CIGR XV World Congress, July 28-31, Chicago, IL, USA. 